\title{
EDITORIAL
}

\section{Early use of surfactant and nitric oxide}

\author{
Journal of Perinatology (2013) 33, 909; doi:10.1038/jp.2013.105
}

In this issue, the article entitled 'Impact of early surfactant and inhaled nitric oxide therapies on outcomes in term/late preterm neonates with moderate hypoxic respiratory failure' by Konduri et al. ${ }^{1}$ poses the possible use of a potentially important combination of treatments for the management of patients with moderate hypoxic respiratory failure. Their post-hoc analysis of patients who were enrolled in an Earlier Use of Nitric Oxide Study suggests that the combination of therapies, surfactant and nitric oxide, appears to improve their overall outcomes.

Clearly, improving outcomes of these patients is an important part of our present management strategies. The possibility that additive treatments may reduce the risk of ECMO/death and shorten hospitalization makes this combination of treatments intriguing and potentially worthwhile.

One question would be why would they be synergistic. There are several possibilities: one would be that, in order for nitric oxide to work, it must reach the alveolus or saccule. ${ }^{2}$ Kinsella et al. ${ }^{3}$ demonstrated that there was greater improvement in the reduction of pulmonary vascular resistance with high-frequency oscillatory ventilation plus nitric oxide compared with conventional ventilation plus nitric oxide. This was believed to be due to more uniform inflation with high-frequency oscillatory ventilation. It is likely that surfactant treatment improves overall uniform lung inflation. This would allow nitric oxide to reach greater areas of the lung exchange surface. Nitric oxide would then diffuse to a larger area of the pulmonary vascular bed with the opportunity to have a greater effect on reducing pulmonary vascular resistance. Second, this would potentially improve ventilation perfusion matching. This combination would also reduce the need for high inspired oxygen concentration and allow for maintaining optimal lung inflation, requiring less assisted ventilatory support. In addition, it has been demonstrated in the animal model that nitric oxide is less effective when the animal is on $100 \%$ oxygen. ${ }^{4}$ This appeared to be due to hyperoxia increasing phosphodiesterase 5 activity. It is also possible that the anti-inflammatory properties of nitric oxide are being offset by the inflammatory properties of high inspired oxygen concentration.

Assisted ventilation, although necessary for survival, is well known to create lung injury. Wung et $a l^{5}{ }^{5}$ and Dworetz et al., ${ }^{6}$ in the mid to late 80 s demonstrated that decreasing ventilatory support to achieve satisfactory gas exchange appeared to decrease the need for ECMO. Neither of these series were randomized nor controlled. Carter et al., ${ }^{7}$ demonstrated that highfrequency oscillatory ventilation in the pre-surfactant era was able to decrease the need for ECMO in late preterm and term patients who had met ECMO criteria. These papers suggest that specific ventilatory strategies have a role in avoiding lung injury and decreasing the need for ECMO. Lack of uniform inflation even in volume-targeted ventilation leads to potential volutrauma of the normally inflated portion of the lung as more volume is delivered to this area with each positive pressure breath, that is, the normally inflated lung will inflate until it becomes less compliant than the atelectatic area causing it to suffer volutrauma.

It will be interesting to see whether surfactant, nitric oxide and specific ventilatory strategies tailored to the different pulmonary pathophysiology of late preterm/term infants with hypoxic respiratory failure can further reduce the outcome of ECMO/death in this patient population. Further controlled trials using surfactant and nitric oxide should specifically address appropriate ventilatory strategies, conventional or high frequency, as they apply to the different pulmonary pathophysiology of these patients. ECMO, although a life-saving technique, certainly increases the risk of secondary complications. Any combination of treatments that allows a reduction in the use of ECMO without adding other complications will be beneficial to these patients.

\section{CONFLICT OF INTEREST}

Dr Null has no real or perceived conflict of interest that relate to this article, but he has financial relationships with commercial entities to disclose: Draeger consultant and Ikaria Speakers Bureau.

DM Null

Primary Children's Medical Center, University of Utah School of Medicine, Salt Lake City, UT, USA E-mail: donald.null@hsc.utah.edu

\section{REFERENCES}

1 Konduri GG, Sokol GM, Van Meurs KP, Singer J, Ambalavanan N, Lee T et al. Impact of early surfactant and inhaled nitric oxide therapies on outcomes in term/late preterm neonates with moderate hypoxic respiratory failure. J Perinatol 2013; 33(12): 944-949.

2 Wessel DL, Adatia I. In: Ignarro L, Murad F (eds) Advances in Pharmacology: Nitric Oxide: Biochemistry, Molecular Biology, and Therapeutic Implications Vol 34. Academic Press: New York, NY, 1995, pp 425-498.

3 Kinsella JP, Truog WE, Walsh WF, Goldberg RN, Bancalari E, Mayock DE et al. Randomized, multicenter trial of inhaled nitric oxide and high-frequency oscillatory ventilation in severe, persistent pulmonary hypertension of the newborn. $J$ Pediatr 1997; 131: 55-62.

4 Farrow KN, Lee KJ, Perez M, Schriewer JM, Wedgwood S, Lakshminrusimha S et al. Brief hyperoxia increases mitochondrial oxidation and increases phosphodiesterase 5 activity in fetal pulmonary artery smooth muscle cells. Antioxid Redox Signal 2012; 17(3): 460-470.

5 Wung JT, James LS, Kilchevsky E, James E.. Management of infants with severe respiratory failure and persistence of the fetal circulation, without hyperventilation. Pediatrics 1985; 76: 488.

6 Dworetz AR, Moya FR, Sabo B, Gladstone I, Gross I.. Survival of infants with persistent pulmonary hypertension without extracorporeal membrane oxygenation. Pediatrics 1989; 84(1): 1-6.

7 Carter JM, Gerstmann DR, Clark RH, Snyder G, Cornish JD, Null JR. DM et al. The roles of high frequency oscillatory ventilation and extracorporeal membrane oxygenation in the treatment of acute neonatal respiratory failure. Pediatrics 1990; 85: 159-164. 